\title{
A proposta pedagógica de leitura de imagens em manuais de língua portuguesa do ensino médio
}

The Pedagogical Proposal of Reading Images in Portuguese Language Manuals for Secondary School

\author{
Hylo Leal Pereira* (iD \\ hyloleal@gmail.com \\ https://orcid.org/0000-0002-9325-6034
}

\author{
Antônia Dilamar Araújo** \\ dilamar.araujo@uece.br \\ https://orcid.org/0000-0002-5031-8725
}

\begin{abstract}
Resumo
O presente artigo propõe uma reflexão sobre o trabalho com imagens constante na subseção Leitura da imagem, presente na coleção Português: contexto, interlocução e sentido, obra integrante do PNLD de 2018, com o intuito de aproximar concepções teóricas atuais relacionadas aos multiletramentos ao fazer pedagógico proposto para o professor de Língua Portuguesa no referido manual de ensino. Acrescentam-se a esse excurso teórico contribuições advindas da multimodalidade, do letramento visual e do letramento crítico. A pesquisa caracteriza-se por uma abordagem qualitativa e analisa duas das oito atividades presentes no terceiro volume da referida coleção. Conclui-se que há lacunas relativas ao trabalho com as teorias dos multiletramentos que, se preenchidas, tendem a potencializar as competências textuais relativas ao adequado letramento visual e crítico dos estudantes.
\end{abstract}

Palavras-chave: Multiletramentos; Letramento visual; Letramento crítico; Ensino de língua portuguesa; Materiais didáticos.

\section{Abstract}

This article proposes to reflect on the work with constant images contained in the subsection of the reading image, present in a Portuguese language textbook collection: context, interlocution, and meaning, an integral work of NPDM (National Program of Didactic Material) in order to approach current theoretical concepts related to multiliteracies when

\footnotetext{
* Doutorando da Universidade Estadual do Ceará - UECE, Fortaleza, Ceará, Brasil, Programa de Pós-Graduação em Linguística Aplicada, Fortaleza, CE, Brasil.

** Professora Titular na Universidade Estadual do Ceará - UECE, Fortaleza, Ceará, Brasil.
}

\section{LINHA D'́́GUA}


doing pedagogical work proposed for the Portuguese Language teacher in the referred teaching manual. Additional contributions from multimodality, visual literacy, and critical literacy will be also inserted as resources in the current text. I ts a qualitative approach research that analyzes two of the eight activities present in the third volume of the referred collection. We concluded that there are gaps related to the work with multiliteracies theories that, if filled, tend to enhance the textual skills related to the adequate students' visual and critical literacy.

Keywords: Multiliteracies; Visual Literacy; Critical Literacy; Portuguese language teaching; Textbooks.

\section{Introdução}

Não é de hoje que os manuais de ensino, em especial aqueles dedicados ao ensino de língua, seja ela materna ou estrangeira, valem-se de forma demasiada e diversificada de repertório imagético na seleta de textos que os compõe; tampouco é recente o estudo dedicado à imagem, sua composição, seus caminhos interpretativos e sua conjunção com o texto elaborado no modo verbal. Entretanto, apesar de toda essa capilaridade dos textos compostos em modo imagético nos manuais de ensino, o emprego, nesses manuais, de reflexões teóricas pautadas nas teorias dos multiletramentos, da multimodalidade e do letramento visual ainda apresenta um longo percurso a ser trilhado.

Chegamos a esta constatação com base na análise de uma das subseções que compõem a obra Português: contexto, interlocução e sentido (ABAURRE; ABAURRE; PONTARA, 2008), livro presente no Programa Nacional do Livro Didático para o ensino médio (PNLD) de 2018 e, por conseguinte, adotado em muitas escolas da rede pública de ensino ${ }^{1}$. Vale salientar que a obra em questão também goza de boa aceitação na rede de escolas privadas Brasil afora, o que podemos concluir com base nas informações disponibilizadas no sítio da Editora Moderna $^{2}$, detentora de seus direitos autorais e editoriais.

Nesse sentido, com base nas concepções teóricas dos multiletramentos, da multimodalidade, do letramento visual e do letramento crítico, analisamos a subseção Lendo a imagem, presente na seção dedicada ao estudo de Literatura do referido manual de ensino, com o propósito de investigar de que modo as concepções desse universo teórico se materializam na proposta de trabalho com a imagem em sala de aula trazida nesta coleção.

O presente artigo está dividido em cinco seções: após esta introdução, na segunda seção, apresentamos as concepções teóricas que servem de base às discussões e reflexões empreendidas sobre as atividades analisadas; na terceira, descrevemos a metodologia

1 Conforme o Guia PNLD 2018, disponível em https://www.fnde.gov.br/index.php/programas/programas-dolivro/pnld/guia-do-livro-didatico/item/11148-guia-pnld-2018. Acesso em: 05 fev. 2020.

2 https://pnld2018.moderna.com.br/-/portugues-contexto-interlocucao-esentido?EhOrigemLista=1\&disciplina=Portugu\%C3\%AAs. Acesso em: 05 fev. 2020.

\section{LINHA D'́GUA}


empregada para levantamento do corpus e a análise dos dados; na quarta compartilhamos as análises realizadas. Ao final, trazemos nossas considerações finais com algumas reflexões últimas decorrentes do nosso processo investigativo, além de propostas que se desdobram dessa investigação.

\section{Um mundo composto por muitos modos semióticos}

Hoje é difícil, quiçá impossível para nós, seres linguajantes, como diria o mestre Maturana, pensarmos em língua, linguagem sem que nos venham à mente as mais diversas imagens. Afirmamos isso porque, enquanto seres que vivem na e pela linguagem em intensa relação de interação com outros seres também imersos nela, dificilmente cogitaríamos, hoje, uma relação de comunicação que prescindisse totalmente de imagens ou gestos em sua composição. Em outros termos: no contexto atual, dificilmente pensaríamos em uma relação de comunicação que estivesse pautada no modo verbal exclusivamente, e isso é, de certa forma, óbvio para nós, que vivemos em uma era de intensa comunicação que se realiza de forma cada vez mais diversificada e, sobretudo, virtualizada.

Ao pensarmos em textos, aqui concebidos como eventos sociocomunicativos para os quais convergem ações de ordem linguística, cognitiva e social (BEAUGRANDE, 1997), concretizados por meio da materialização da linguagem arquitetada em gêneros, de forma análoga, dificilmente prescindiríamos do modo imagético ou mesmo gestual, para sua composição. Desse modo, como professores de língua, falar de língua, de linguagem e de textos em nossas aulas é, segundo Kress e van Leewen (1996), falar de textos que se apresentam em vários modos semióticos, compostos por imagens, cores, sons, palavras, ritmos, dentre outros.

Acrescente-se que, na qualidade de estudiosos da linguagem, é-nos natural a compreensão de que os textos estão imersos em relações de contexto que lhes são constitutivas, de modo que compreendemos haver uma interrelação ontológica entre eles e suas situações de comunicação e produção, ou, nos termos de Hanks (2008), uma relação de emergência e de incorporação, caracterizada como contexto, que é compreendida como parte constitutiva do próprio texto. Por isso, é inegável dizer que estamos imersos em uma forte relação entre o trabalho com a língua, com o texto, a dimensão cultural em que o texto é produzido e o contexto de comunicação atual, fortemente influenciado pelas tecnologias da informação e da comunicação (doravante TICs).

Toda essa reflexão leva-nos à assunção do conceito de multiletramentos, postulado inicialmente pelo Grupo de Nova Londres ${ }^{3}$ (1996) e seguido por vários outros estudiosos da seara da linguagem. Em sua concepção, o Grupo chama-nos a atenção para dois pontos importantes: "a multiplicidade de linguagens, semioses e mídias envolvidas na criação de

3 Também referido nesse artigo como New London Group, em função da manutenção da nomenclatura lida nos textos originais e referenciada ao final do texto.

\section{LINHA DÁGUA}


significação para os textos multimodais contemporâneos; a pluralidade e a diversidade cultural trazidas pelos autores/leitores contemporâneos a essa criação de significado" (ROJO, 2013, p. 14 , grifos da autora).

Dessa forma, compreendendo as relações estabelecidas por esses dois pontos e o trabalho pedagógico atualmente proposto para o ensino de língua, torna-se necessária a introdução de reflexões pautadas nos multiletramentos nas práticas pedagógicas e, de forma ainda mais especial, nos manuais de ensino, uma vez que visam dar subsídio a essas práticas, sobretudo, ao entenderem a escola como um campo de preparação do jovem para o exercício pleno da cidadania. Nesse sentido, a teoria dos multiletramentos proposta pelo Grupo de Nova Londres (1996) também está relacionada à formação do educando e à sua atuação na vida pósescolar, na chamada vida produtiva, devendo essa ser uma preocupação eminente do professor.

Em sua defesa da pedagogia dos multiletramentos, o Grupo de Nova Londres (1996) aponta como uma das principais reponsabilidades do professor a consideração das implicações do seu fazer pedagógico na vida profissional produtiva dos estudantes. Em seus termos, "Com uma vida profissional vem uma nova linguagem. Boa parte dessa mudança é o resultado de novas tecnologias, como os modos iconográfico, textual e de tela de interação com máquinas automatizadas (NEW LONDON GROUP, 1996, p. 11, tradução livre ${ }^{4}$ ).

Ademais, dentre outros pontos relevantes da teoria dos multiletramentos, destacamos para nossa discussão sua defesa relacionada ao direito do estudante de, ao lidar com artefatos linguísticos múltiplos, ser capaz de realizar as interconexões necessárias à sua interpretação, sendo esse um dos objetivos centrais dessa teoria, uma vez entendido que "a comunicação transcultural e o diálogo negociado de diferentes idiomas e discursos podem ser uma base para a participação, o acesso e a criatividade [...] em que as pessoas sentem que suas diferentes origens e experiências são genuinamente valorizadas." (NEW LONDON GROUP, 1996, p. 13, tradução livre ${ }^{5}$.

Neste trabalho, analisaremos propostas de atividades de interpretação textual para estudantes que estão baseadas em textos multimodais variados, cujos contextos, além de bastante diversos, apresentam forte relação histórica e são utilizados pelas autoras como catalisador das relações interpretativas. Nesse sentido, compreender tais textos certamente demandará do leitor um forte apelo à sua capacidade de estabelecer relações de comunicação transcultural.

A partir dos conceitos de multiletramentos e em complemento a eles, trazemos para este estudo algumas contribuições relativas ao letramento crítico, as quais julgamos pertinentes ao

4 "With a new worklife comes a new language. A good deal of this change is the result of new technologies such as the iconographic, text, and screen-based modes of interacting with automated machinery" (NEW LONDON GROUP, 1996, p. 11).

5 "Cross-cultural communication and the negotiated dialogue of different languages and discourses can be a basis for worker participation access and creativity [...] in which people feel that their different backgrounds and experiences are genuinely valued" (NEW LONDON GROUP, 1996, p. 13).

\section{LINHA DÁGUA}


trabalho com a leitura a partir de uma perspectiva de ensino-aprendizagem que privilegia a interação autor-leitor-texto numa relação de intercomplementaridade, em que o significado não reside/está dado a priori em nenhum desses três elementos, mas emerge da relação de interação que se estabelece a partir da leitura, entendida aqui como uma atividade complexa (FRANCO, 2011).

Trazer o letramento crítico para a discussão é ainda uma forma de evidenciar a interrelação essencial entre a linguagem e a vida em sociedade, a partir da perspectiva de que

em um mundo que é rico em diferenças, ainda é provável que haja intolerância e medo do outro. Como a diferença é estruturada em relação ao poder, ao acesso desigual a recursos com base em gênero, raça, etnia, idioma, capacidade, sexualidade, nacionalidade e classe continuará a produzir privilégios e ressentimentos. (JANKS, 2012, p. 150, tradução livre ${ }^{6}$ ).

Dessa forma, por entendermos não ser suficiente a decodificação/identificação das informações em textos compostos por diversos modos, para que seja realizada de forma plena sua leitura, julgamos necessário ao leitor o conhecimento, ainda que precípuo, dessas relações de poder imanentes à interação por meio da língua/linguagem, compreendendo quais são seus objetivos, suas focalizações, para, a partir daí, ter-se mais clareza sobre as possiblidades interpretativas de um texto.

Nesse sentido, não cabe à escola ou ao professor apenas instrumentalizar o estudante para o processo leitor baseado na decodificação, mas, como nos diz Street (2014), há que ser desenvolvido no indivíduo uma relação de letramento social (crítico) pautado nas necessidades do sujeito e com foco na resolução de situações cotidianas. Essa é uma perspectiva levantada pelo autor que se opõe ao que ele chama de letramento autônomo, um tipo de letramento que não se preocupa com as particularidades dos sujeitos, mas que está em busca da padronização dos processos de letramento, portanto, não se estabelecendo um fazer educacional crítico.

Há ainda que se atentar para as novas relações de leitura e produção de textos oportunizadas no século XXI pelas TICs a partir de vários aspectos, dentre eles o de autoria. "A autoria atualmente é desafiada pelas novas formas de produção de texto: misturas, miscelâneas, colagens, recortes e recontextualizações são práticas tomadas pela geração usuária da internet 2.0" (JANKS, 2012, p. 152, tradução livre ${ }^{7}$ ). Desse modo, faz parte do trabalho com o letramento crítico a percepção desses 'movimentos linguísticos' tanto nos processos de produção quanto de interpretação de textos, com vistas a uma curadoria necessária à massiva quantidade de dados, muitos deles eticamente questionáveis ${ }^{8}$, aos quais as TICs têm possibilitado nosso acesso (ROJO, 2013).

6 "In a world that is rich with difference, there is still likely to be intolerance and fear of the other. Because difference is structured in relation to power, unequal access to resources based on gender, race, ethnicity, language, ability, sexuality, nationality and class will continue to produce privilege and resentment" (JANKS, 2012, p. 150).

7 "Authorship is further challenged by new forms of text making: mixing, mashing, cutting, pasting and recontextualizing are taken-for-granted practices of the net-generation" (JANKS, 2012, p. 152).

8 Referimo-nos, aqui, à crescente onda negacionista, bem como às fontes produtoras de fake news, que encontram no ambiente virtual ampliadas possiblidades de produção e disseminação de informações dessa natureza.

\section{LINHA D'ÁGUA}


Partindo com mais objetividade para o campo dos textos compostos por imagens, que constituem o foco de nossa análise, trazemos à discussão algumas considerações relacionadas aos estudos do letramento visual, com base na concepção de que letramento visual caracterizase como "a habilidade de 'ler', interpretar e entender informações presentes em imagens pictóricas ou gráficas associada à habilidade de tornar informação de todos os tipos em imagens, gráficos ou formas que auxiliem na comunicação da informação" (WILEMAN, 1993 apud STOKES, 2002, p. 12, tradução livre, grifo do autor ${ }^{9}$ ), ou ainda, "a habilidade de interpretar mensagens visuais de forma adequada, além de criar esse tipo de mensagens" (HEINICH et al., 1999 apud STOKES, 2002, p. 12, tradução livre $\left.{ }^{10}\right)$. Isso posto, podemos observar que o letramento visual se caracteriza tanto por relações de interpretação quanto pelas relações de produção de texto. No presente estudo, trabalharemos com foco na investigação das relações de interpretação, que é a proposta pedagógica presente no corpus da pesquisa.

Após esse excurso relacionado aos multiletramentos e ao letramento crítico, mostramonos convencidos da necessidade de se trabalhar de forma intencional e refletida com textos que tenham em sua composição o modo imagético, não no intuito de relegá-los a este ou àquele plano, mas por entendê-los como essenciais às relações de comunicação vigentes, de modo que não nos faria sentido o fazer pedagógico que não contemplasse o letramento visual, sobretudo, a partir de um contexto que traz uma série de evidências do quão é pedagogicamente positivo o emprego de gêneros multimodais na relação ensino-aprendizagem (DIONÍSIO, 2011). Entendemos ser necessária ainda que

uma abordagem pedagógica alternativa, que vise dar conta de textos híbridos, compostos por texto(s) e imagem(ns), e que busque apreender tanto suas funções textuais quanto contextuais, não se propõe, em absoluto, substituir ou subestimar a prática educacional vigente, mas complementá-la, a fim de contemplar seus componentes culturais e situacionais (ALMEIDA, 2009, p. 189).

Ainda em relação ao letramento visual, estudos apontam para a vantagem de se trabalhar com essa perspectiva linguística em sala de aula, a exemplo de Chanlin (1998), citado por Stokes (2002), cujos estudos apontam para o incremento na aprendizagem a partir do uso de imagens e ou animações em sala de aula. Em contrapartida, essas pesquisas sugerem que a eficácia do design visual na aprendizagem está relacionada ao conhecimento prévio dos estudantes e ao nível de leitura em que se encontram (STOKES, 2002).

Ao relacionarmos essas concepções ao corpus em análise, percebemos que fica bastante a cargo do professor estabelecer essas relações, bem como perceber esses diferentes níveis de leitura e de conhecimento prévio, de modo que também caberá a ele traçar estratégias eficazes

9 "The ability to 'read', interpret, and understand information presented in pictorial or graphic images. Associated with visual literacy is visual thinking, described as the ability to turn information of all types into pictures, graphics, or forms that help communicate the information" (WILEMAN, 1993 apud STOKES, 2002, p. 12).

10 "The learned ability to interpret visual messages accurately and to create such messages" (HEINICH et al., 1999 apud STOKES, 2002, p. 12).

\section{LINHA DÁGUA}


para, a partir desse panorama, propor alternativas pedagógicas que busquem a equidade dos processos de ensino-aprendizagem no trabalho com os textos, o que será pormenorizado na seção dedicada às análises.

Por fim, ainda à guisa de referencial teórico, pinçamos algumas contribuições que se mostram caras a esse processo de análise da proposta de letramento visual investigada no corpus, a partir de contribuições dos estudos da multimodalidade e da Gramática do Design Visual (doravante GDV).

Cumpre enfatizar que, por tratar-se de um campo muito vasto, e por ess,e não ser o escopo central de análise deste estudo, trazemos uma conceituação rápida sobre multimodalidade além de introduzirmos apenas as categorias mais gerais de análise de imagens a partir da GDV. Deste modo, não é nossa pretensão, para este estudo, estabelecer alguma relação de aprofundamento teórico nas bases conceituais de um e de outro campo, mas trazer à tona conceitos fundantes que podem orientar nosso olhar investigativo quando da análise das atividades presentes no corpus. A partir de critérios didáticos, optamos por, primeiramente, apresentar o conceito de multimodalidade para, na sequência, adentrarmos as categorias da GDV.

Datado de 1920, o termo multimodalidade estreia nos estudos da psicologia da percepção denotando o efeito que diferentes percepções sensoriais têm umas sobre as outras. De forma mais recente, já no campo da linguística, o termo denota o uso integrado de diferentes elementos de comunicação, como a língua, imagens, sons e música em textos e eventos compostos por diferentes modos semióticos (VAN LEEUWEN, 2011). Em meados da década de 90, inspirados na concepção de língua enquanto sistema empreendida por Halliday (1985) e Halliday e Matthiessen, a partir de sua Gramática Sistêmico-Funcional (2014), os conceitos de multimodalidade passaram a permear a agenda de estudos da linguagem e do letramento no campo da Linguística Aplicada.

Dentre os estudos centrados na multimodalidade e vários outros, destacamos a elaboração da Gramática do Design Visual por Kress e van Leeuwen (1996) como um marco teórico no estudo das imagens, que, também partindo das contribuições de Halliday (1985), busca traçar um padrão sobre a apresentação dos textos de composição multimodal (especialmente em modo imagético), a partir do padrão ocidental de composição textual, não como forma de descrever todas as possiblidades organizacionais, composicionais e interpretativas de um texto dotado de imagens, mas em defesa da "conscientização das imagens enquanto códigos de significado imbuídos de estruturas sintáticas próprias e dotadas de significado potencial" (ALMEIDA, 2009, p. 175). Acrescente-se ainda que a GDV não toma as imagens que analisa como formas neutras desprovidas de contextualização para construção de sentidos (ALMEIDA, 2009). De forma breve, apresentamos as três metafunções propostas pela GDV para a análise do corpus: metafunção representacional, interativa e composicional.

A metafunção representacional "comunica a relação estabelecida entre os participantes internos de uma dada composição imagética” (ALMEIDA, 2009, p. 178). É a partir dela que se 
analisam processos narrativos relativos às representações de ações e eventos dinâmicos e processos conceituais relativos às representações de ordem estática (KRESS; VAN LEEUWEN, 1996).

A metafunção interativa, por sua vez, analisa aspectos que tratam das relações estabelecidas entre imagem e espectador/leitor como contato, distância social, perspectiva e modalidade relacionados à imagem. É a partir dela que se pode analisar características da imagem como enquadramento, contato visual entre a imagem e o espectador, perspectiva de plano de representação e nível de realidade/abstração da imagem (KRESS; VAN LEEUWEN, 1996).

Por fim, a metafunção composicional ocupa-se em "descrever como os elementos composicionais de uma dada imagem se articulam entre si para expressar ideias específicas e formar um todo coerente" (ALMEIDA, 2009, p. 185), a partir de categorias como valor da informação, saliência e estruturação.

Ainda que apresentadas de forma muito elementar, acreditamos que as categorias da GDV se constituem como uma

ferramenta de leitura de composições multimodais, adequada a um ambiente de ensino e aprendizagem para a prática da habilidade de ver integrada à habilidade de ler e, consequentemente, à pedagogia dos multiletramentos, na perspectiva da semiótica social para a qual a língua é apenas uma das formas de representação e, portanto, é preciso ensinar e aprender a integrar diferentes modos e recursos semióticos (BARBOSA, 2017 p. 341).

Com o objetivo de ilustrar algumas possiblidades analíticas a partir das categorias da GDV que trazemos para este estudo, compartilhamos a seguir a análise rápida de uma imagem de livre circulação na internet. Vale registrar que, embora os pesquisadores tendam a analisar as metafunções da linguagem separadamente, elas ocorrem simultaneamente na construção de significados para representação e comunicação.

Figura 1. Moça na varanda tirando fotos da paisagem externa

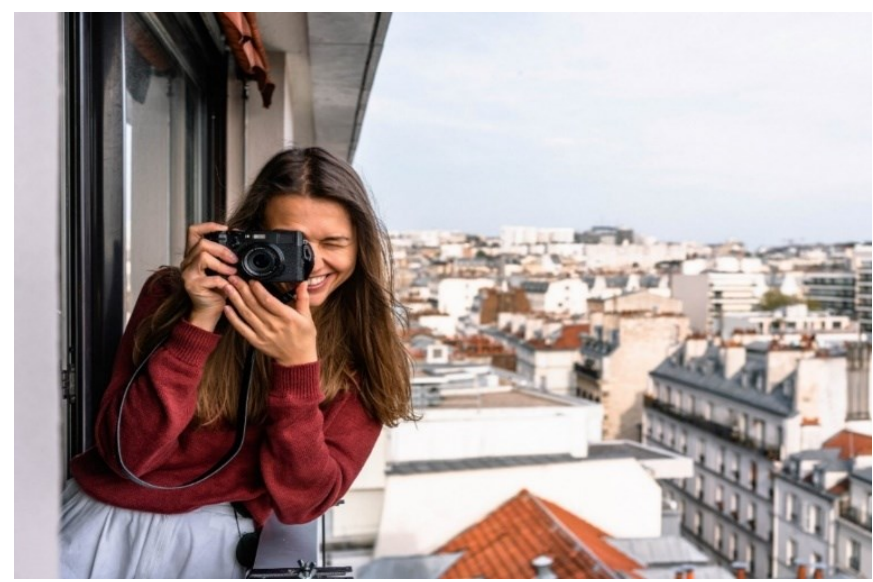

Fonte: https:/www.pexels.com/pt-br/foto/mulher-na-varanda-usando-câmera. Acesso em: 13 mar. 2021.

\section{LINHA DÁGUA}


A Figura 1, extraída do site de imagens gratuitas pexels.com, mostra uma jovem fotógrafa sorridente de cabelos longos castanhos, elegantemente vestida em uma saia branca e um suéter na cor vinho, na varanda do prédio no qual provavelmente reside, tirando fotos com sua câmera da paisagem externa. Em uma perspectiva da semiótica social, a metafunção representacional nesse texto imagético se organiza em torno da estrutura narrativa, porque vemos uma jovem em ação, em movimento, o corpo levemente inclinado, o olho direito fechado, segurando com as duas mãos (vetores) uma câmera posicionada à altura do olho esquerdo, mirando o alvo de sua foto (outro vetor que indica ação), o qual o leitor pode imaginar qual seja, a partir da paisagem à sua volta. Por ela estar em ação, ela é uma participante representada (ator) que se utiliza de um instrumento, a câmera, para mirar e clicar o seu alvo (a meta) não visível para o leitor, caracterizando uma relação não-transacional nessa estrutura narrativa. Por ser uma foto real, as circunstâncias que compõem essa narrativa são o cenário, ambiente com sua caracterização: ruas com prédios baixos, o céu nublado e o artefato usado pela fotógrafa para tirar a foto.

A participante representada na imagem, a fotógrafa, está na varanda em posição frontal, cujo olhar, por meio da câmera, em direção ao leitor (contato por demanda), cria um elo de interação imaginária (metafunção interativa), que demanda do leitor atenção e desperta sentimentos subjetivos de aproximação, identificação e intimidade. A beleza da fotógrafa e do lugar em que ela se encontra chama a atenção do leitor e o convida a apreciar e interagir com a imagem. O cenário retratado com casas e prédios, a fotógrafa com sua câmera, as cores e ângulos utilizados na imagem indicam uma modalidade natural, criando um efeito de realidade e de forte apelo para o leitor de que ele pode também ser fotógrafo.

Se examinarmos a estruturação e a composição dos elementos da imagem (metafunção composicional), podemos afirmar que as informações a serem apreendidas estão organizadas da esquerda para a direita (dado e novo), da fotógrafa com sua câmera, que se apresenta como uma informação familiar (dada), e da rua com os prédios e casas até a cidade retratada à direita, que se apresenta como informação nova para o leitor, despertando curiosidade para se identificar o lugar. O destaque dado à fotógrafa, em termos de tamanho, ênfase nas cores de sua roupa, no ângulo do corpo, chama a atenção do leitor (saliência), remetendo à atuação profissional da participante representada na imagem como uma profissão a ser valorizada. Os elementos que compõem a imagem se conectam de forma coerente, trazendo harmonia textual, com o propósito de convidar o leitor a apreciar a informação veiculada no texto imagético.

Essa análise multimodal da imagem possibilita examinar como os recursos semióticos, como vetores, ângulos, formas, saliência e cores, se integram na produção de significados e convidam o leitor à apreciação e reflexão sobre as informações representadas e veiculadas na imagem em foco. É importante ressaltar que os professores em sala de aula chamem a atenção dos alunos para analisarem imagens como textos, além dos textos constituídos por mais de um modo semiótico, para a compreensão de significados, considerando as escolhas do produtor dentro de um contexto social.

\section{LINHA DÁGUA}


É a partir desse quadro teórico que passaremos às análises das propostas de atividade elencadas no corpus selecionado.

\section{Metodologia}

Neste estudo, desenvolvemos uma pesquisa de natureza aplicada, de abordagem qualitativa, a partir de um procedimento de análise descritiva. Analisamos o terceiro de um total de três volumes da coleção Português: contexto, interlocução e sentido (ABAURRE; ABAURRE; PONTARA, 2008), coleção participante do PNLD do ensino médio desde 2012 até sua versão mais atual: 2018 .

Dessa coleção, analisamos especificamente a subseção Leitura da imagem, presente na seção dedicada aos estudos de Literatura. A referida subseção traz oito atividades por volume, dentre as quais analisamos duas.

No âmbito de nossa análise, investigamos o trabalho pedagógico proposto aos estudantes e professores pelas autoras, com vistas a analisar a relação entre tais propostas pedagógicas e as teorias relativas aos estudos dos multiletramentos, do letramento crítico, do letramento visual e da multimodalidade.

\section{Lendo imagens}

Iniciamos esta seção com base na reflexão de o quão é necessário e ainda incipiente o trabalho mais aprofundado com a leitura de imagens e/ou composições textuais mistas, seja nas aulas de língua ou de outras áreas do conhecimento. Nesse sentido, cabe valorizar o esforço empreendido pelas autoras da coleção Português: contexto, interlocução e sentido (ABAURRE; ABAURRE; PONTARA, 2008), uma vez que, além do uso frequente de imagens, infográficos e esquemas verbo-visuais, dedicam, no âmbito do estudo da literatura, uma subseção especificamente voltada ao trabalho com os letramentos visuais, ainda que os teóricos dessa corrente de estudo não estejam contemplados na bibliografia apontada como base para referida subseção ou mesmo para o restante da obra. Feita essa ressalva, passemos à análise das atividades propostas pelas autoras.

A subseção Leitura da imagem está presente em toda a coleção, sempre nos capítulos de literatura e sempre como abertura do capítulo. Na edição do professor, em um capítulo intitulado Guia dos recursos, as autoras explanam sobre a metodologia empregada por elas para a composição da coleção. Especificamente em relação à subseção Leitura da imagem, dizemnos que se trata de um

conjunto de questões que têm por objetivo 'direcionar' o olhar do aluno para os aspectos mais relevantes da produção artística de uma estética específica, ou para elementos pictóricos que podem auxiliá-lo a compreender conceitos em torno dos 
quais se organiza o capítulo (ABAURRE; ABAURRE; PONTARA, 2008, p. 9, grifos no original).

Trazem ainda, à guisa de sugestão de trabalho, a orientação de que as questões apresentadas possam ser utilizadas como "ponto de partida para a realização de uma atividade oral em que os alunos discutam as possiblidades de leituras da imagem reproduzida" (ABAURRE; ABAURRE; PONTARA, 2008, p. 9).

Para além dessas orientações, nada mais é dito para o professor adotante da coleção, a não ser as rápidas orientações de procedimento metodológico presentes na própria proposta de atividade $^{11}$, as quais reproduziremos mais adiante. Além disso, não são feitas quaisquer considerações de cunho teórico ou ainda apontadas referências bibliográficas que possam ser buscadas pelo professor de modo a embasar teoricamente essa discussão proposta a partir da reflexão sobre a imagem.

A primeira proposta de atividade a analisarmos traz o seguinte:

Figura 2. Imagem da atividade 1 analisada

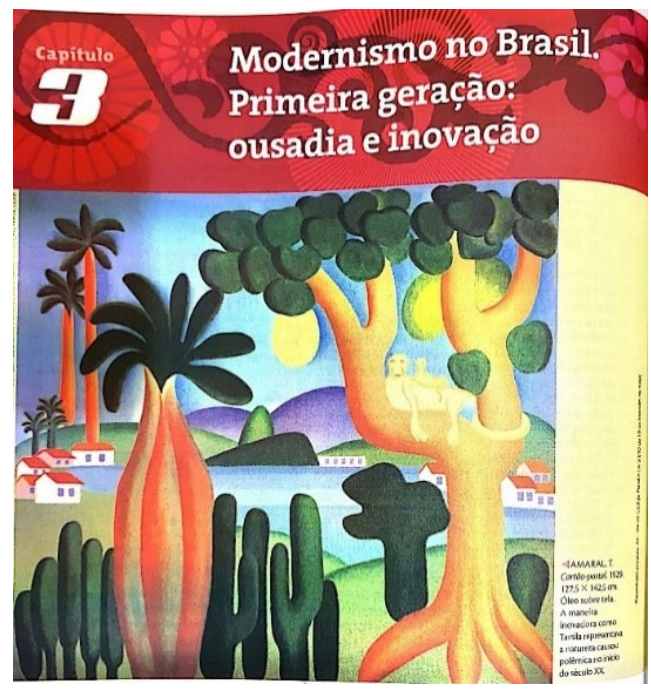

Fonte: ABAURRE; ABAURRE; PONTARA, 2008, p. 68.

11 Essas orientações apresentam-se em destaque e apenas na versão do professor, como é próprio dos manuais didáticos.

\section{LINHA D'ÁGUA}


Figura 3. Atividade 1 analisada

$\boldsymbol{F}^{\text {evereiro de 1922. No elegante Teatro Municipal, a elite assiste }}$ $\boldsymbol{F}$ assombrada à apresentação de irreverentes e jovens artistas: sua arte redefine de modo ousado os padrões estéticos em voga. A reação à apresentação é violenta e imediata. Neste capitulo, saiba tudo o que aconteceu e conheça os caminhos da literatura brasileira inaugurados pela Semana de Arte Moderna.

\$) Leitura da imagem $\quad \begin{aligned} & \text { sugerimos que todas as questōes sejam respondidas oralmente } \\ & \text { para que os alunos possam trocar impressōes e ideias. }\end{aligned}$

1. Que elementos da natureza estão representados na página ao lado?

2. No quadro Cartão-postal, Tarsila pintou imagens caracteristicas do Rio de Janeiro. Que aspectos da natureza ela escolheu?

$\checkmark$ A paisagem pintada por Tarsila do Amaral é uma representação estilizada do Rio de Janeiro, com o Pão de Açúcar ocupando o centro da tela. Que relação a artista estabelece entre o título da obra, o cenário escolhido e a forma como foi representado?

3. Observe o quadro Floresta virgem do Brasil, do Conde de Clarac.

$\checkmark$ A natureza brasileira é representada por Clarac de modo muito diferente da visão de Tarsila. Explique por quê, considerando as possiveis intenções de cada obra.

4. Em Cartão-postal, o uso das cores fortes e o modo como os elementos da natureza foram recriados sugerem uma releitura menos formal, mais alegre e irreverente. Como isso fica evidente no quadro?

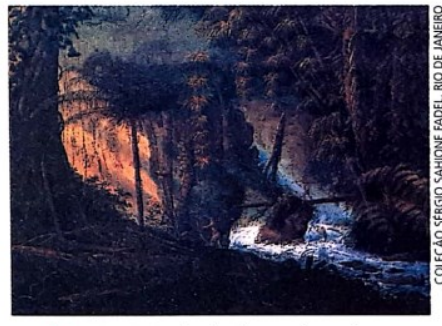

$\triangle$ CLARAC, Conde de. Floresta virgem do Brasil. 1816. Guache sobre papel, $61 \times 81,6 \mathrm{~cm}$.

Fonte: ABAURRE; ABAURRE; PONTARA, 2008, p. 69.

Figura 4. ${ }^{12}$ Ampliação de Floresta Virgem, presente na atividade 1 analisada

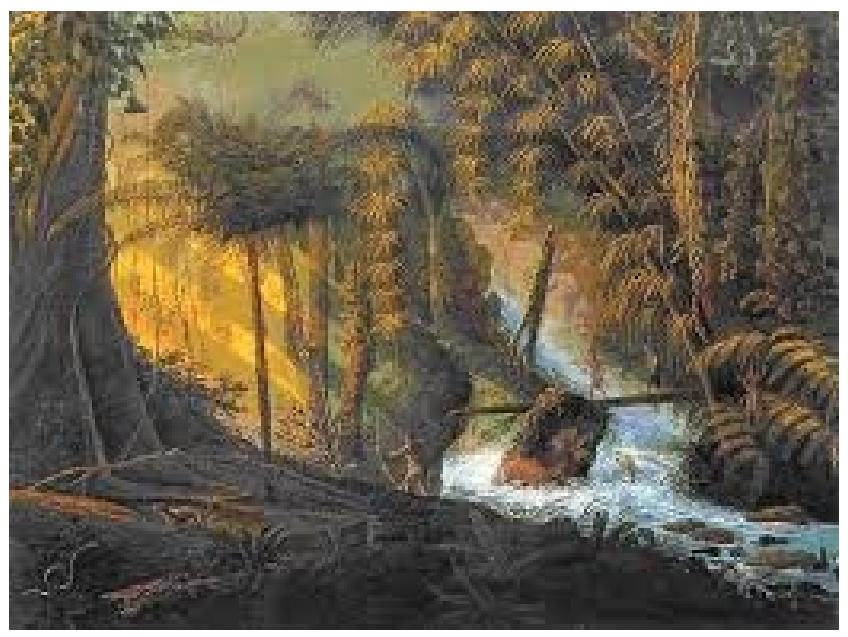

Fonte: CLARAC, Conde de. Floresta virgem do Brasil. 1816. Guache sobre papel, 61 x 81,6 cm. Disponível em: http://escolaameliodecarvalhobais.blogspot.com/2010/05/aula-de-literaturaromantismo.html. Acesso em: 10 jan. 2020.

A subseção Leitura da imagem é antecedida por um breve parágrafo de abertura, que exerce a função de contextualização. Pela própria tradição ocidental de leitura - de cima para

12 Por questões de visibilidade, ampliamos aqui a pintura de Conde de Clarac, presente na Figura 3, que integra a seção Leitura da imagem.

\section{LINHA D'́GUA}


baixo e da esquerda para a direita - o estudante é levado naturalmente à leitura desse parágrafo de contextualização, o que já se configura como um início de relação entre o modo pictórico da imagem (Cartão - postal) e o modo verbal do texto (Figura 2). Essa possiblidade de interrelação entre textos compostos por distintos modos semióticos faz parte dos objetivos gerais do letramento visual (STOKES, 2002). Na sequência, temos a subseção propriamente dita e os questionamentos/propostas de reflexão suscitadas verbalmente (Figuras 3 e 4).

Nessa proposta de atividade, as autoras iniciam a exploração da imagem de forma superficial, ao questionar os leitores sobre quais os elementos retratados na imagem e o que é adequado para um primeiro contato. Por tratar-se de uma imagem cuja representação não é realista, acreditamos que esse seja um mote inicial interessante a ser discutido com os estudantes. As autoras, inclusive, ensaiam algo nesse sentido, quando, no segundo questionamento, ao indagar sobre aspectos da natureza carioca, trazem a informação de que a pintura de Tarsila é estilizada, contudo, não fazem considerações sobre o que representa ser uma pintura estilizada. Na terceira questão, as autoras se valem de uma obra de Conde de Clarac, Floresta virgem do Brasil (1816), apresentada em segundo plano, indagando ao estudante sobre a diferença entre as formas de se retratar a natureza escolhidas pelos dois artistas. Elas solicitam ao leitor, ainda, que seja estruturada uma comparação entre as imagens, a partir de uma consideração relacionada às intenções de cada autor ao retratar a paisagem brasileira.

A partir dessa proposta de exploração da imagem, percebe-se a preocupação das autoras com as relações interpretativas intertextuais, além de uma clara intenção de fazer o estudante refletir sobre as diversas formas de (re)produção de imagens utilizadas pelos artistas.

Do ponto de vista da perspectiva dos multiletramentos, percebemos que a pluralidade cultural é, sim, explorada, uma vez que são propostas relações comparativas, inclusive, entre as diferentes apresentações artísticas, ainda que sob a mesma linguagem: a das artes plásticas. Entretanto, a proposta de atividade deixa muito a cargo do professor a condução dessa discussão a partir de algum referencial teórico que ela mesma não aponta. Por meio dessa atividade, categorias próprias da Gramática do Design Visual, tal como a metafunção interacional, poderiam ser trazidas à discussão, para fundamentar cientificamente, por exemplo, a modalidade abstrata no quadro de pintura estilizada do Rio de Janeiro, de Tarsila do Amaral, frente à modalidade naturalista adotada na pintura de Conde de Clarac.

Há ainda outros momentos, como quando do comentário das autoras sobre o posicionamento do Pão de Açúcar ao centro da tela ou da utilização de cores específicas, ditas 'fortes' no enunciado, que poderiam ser melhor explorados no manual e que ficam a cargo do professor, ressalte-se que sem qualquer apoio de embasamento teórico fornecido pelas autoras. Em relação a esses aspectos, a exploração da metafunção composicional, certamente, traria grandes contribuições para a exploração de o porquê de o Pão de Açúcar estar centralizado, ainda que distante ou pouco saliente, bem como o porquê do emprego de cores saturadas e quais os efeitos de sentido desencadeados a partir dessas escolhas por parte do pintor.

\section{LINHA DÁGUA}


Do ponto de vista do letramento crítico, percebe-se, de forma muito rápida, uma incursão nessa seara, no âmbito da quarta questão ${ }^{13}$, quando da proposição de que o leitor analise o uso das cores fortes e o modo abstrato (ou menos naturalista) com que a obra se apresenta, associando essas escolhas artísticas a uma relação de irreverência. No entanto, essa exploração crítica das relações de letramento também fica a cargo do professor que conduz a aula e ainda de forma muito intuitiva, caso essa condução venha a depender apenas das condições apresentadas/sugeridas pelo manual didático.

Na segunda proposta de atividade analisada, temos o seguinte:

Figura 5. Imagem da atividade 2 analisada

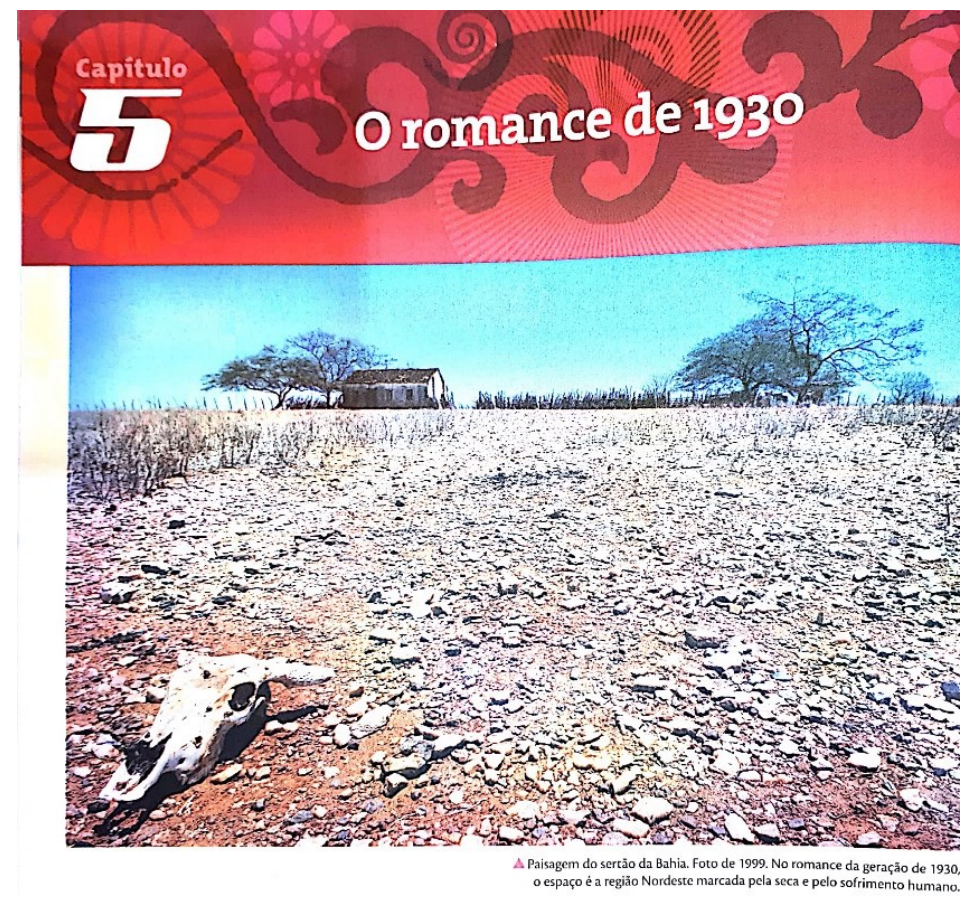

Fonte: ABAURRE; ABAURRE; PONTARA, 2008, p. 124.

13 Em Cartão-postal, o uso das cores fortes e o modo como os elementos da natureza foram recriados sugerem uma releitura menos formal, mais alegre e irreverente. Como isso fica evidente no quadro?

\section{LINHA D'ÁGUA}


Figura 6. Atividade 2 analisada

Brasil testemunhou, na década de 1930, uma explosão

do romance. Preocupados com o país em que viviam, escritores usaram a narrativa como instrumento de denúncia de uma realidade que, principalmente na região Nordeste, condena milhares de brasileiros à miséria. Neste capitulo, você verá como o regionalismo dominou a ficção da segunda geração modernista.

2) Leitura da imagem $\quad \begin{aligned} & \text { Sugerimos que todas as questões sejam respondi- } \\ & \text { das oralmente para que os alunos possam trocar } \\ & \text { impressões e ideias. }\end{aligned}$

1. Descreva, brevemente, a imagem de abertura.

2. Que impressão o espaço retratado provoca no observador?

3. Uma caveira de boi aparece em primeiro plano. Que leitura da foto o fotógrafo sugere com esse destaque?

Fonte: ABAURRE; ABAURRE; PONTARA, 2008, p. 125.

Seguindo a metodologia adotada para essa subseção, entre a imagem propriamente dita e a proposta de leitura da imagem, há um parágrafo que serve de contextualização e explicação para o leitor tanto para o que será estudado no capítulo quanto para as relações de interpretação da própria imagem. Trata-se de um encaminhamento da leitura esperado pelas autoras, ou seja: são pistas que podem servir de base à interpretação que será realizada pelo leitor.

Essa proposta de atividade é composta basicamente por três questionamentos, todos breves e objetivos, diferentemente do que pudemos analisar na atividade anterior, o que mostra que, apesar de seguir um padrão metodológico, conforme descrito no Guia de recursos (ABAURRE; ABAURRE; PONTARA, 2008, p. 9), essa estabilidade é relativa e se adapta ao que as autoras julgam como adequado para a abordagem de cada capítulo e de cada texto. Essa estabilidade relativa é vista de forma positiva por nós, por compreendermos que a produção de material didático não deve privilegiar a forma ou a padronização de sequências metodológicas rígidas, mas a exploração dos efeitos de sentido possíveis e necessários a partir da leitura dos textos.

Inicialmente, pede-se que os estudantes descrevam, de forma breve, a imagem em análise (questão 1). Similar à atividade anterior, inicia-se por um questionamento superficial que objetiva mobilizar relações interpretativas mínimas e essenciais ao entendimento do texto. Na sequência, pergunta-se ao estudante sobre suas impressões acerca da imagem (questão 2), momento em que o leitor é levado a refletir a partir de sua própria vivência, seus conhecimentos de mundo sobre o sentido da imagem, que certamente variará de acordo com as experiências de cada leitor, em especial se atentarmos para o fato de esse ser um manual de adoção nacional, e dessa forma, tanto essa imagem pode causar estranheza ao leitor, quanto intensa familiaridade. Por fim, as autoras fazem alusão mais direta ao elemento de maior saliência da imagem: a 
caveira de boi, solicitando aos estudantes que reflitam sobre as intenções do fotógrafo ao capturar essa imagem a partir de determinada perspectiva e enquadramento (questão 3), ainda que não empreguem esses termos técnicos.

No que diz respeito às relações gerais dos multiletramentos, entendemos que o texto é pertinente ao necessário discurso sobre diversidade cultural e transculturalidade, apesar disso não ser acionado de forma explícita na proposta de atividade, ficando a cargo da sensibilidade e do referencial teórico pessoal do professor. O comentário que fizemos no parágrafo anterior sobre os diversos significados que esse texto pode assumir a depender do leitor poderia seguramente ser contemplado na discussão proposta pelas autoras para essa imagem, de modo a garantir a indução dessa reflexão sobre a transculturalidade. Tal indagação também poderia ser vista como um gatilho interessante para o despertar do letramento crítico em relação a esse texto. Com isso, não estamos afirmando taxativamente que a segunda questão, da forma como está posta, não colabore para suscitar reflexões relacionadas aos letramentos visual e crítico dos estudantes, apesar de concebermos que, mais uma vez, o manual deixa a responsabilidade para o professor desenvolver e adaptar esse tipo de conhecimento teórico mais aprofundado e significativo às atividades do livro didático com os estudantes na sala de aula.

No que diz respeito às categorias da GDV, acreditamos que elas poderiam contribuir bastante com a discussão suscitada a partir da questão 3. Nesse sentido, reflexões relacionadas à metafunção composicional, tais como valor da informação (topo / base: ideal / real) e saliência (primeiro plano / plano de fundo), certamente serviriam como bases teóricas valorosas para a interpretação da mensagem elaborada pelo fotógrafo.

Reflexões que partissem da metafunção interacional, especialmente relacionadas à modalidade naturalista, também trariam contribuições relevantes para essa discussão, podendo ainda serem relacionadas ao próprio recorte temático da imagem, tão presente na produção literária a que ela faz menção: o romance da década de 30 .

Que fique claro que não estamos advogando, necessariamente, para que sejam levadas ao currículo do ensino médio nomenclaturas e terminologias oriundas da GDV, ainda que as entendamos como "uma metalinguagem a ser ensinada em ambiente formal de aprendizagem, facilitando a leitura de composições multimodais" (BARBOSA, 2017, p. 342). Acreditamos que esses conceitos possam ser explorados de forma intencional pelo professor, especialmente, a partir de uma mobilização, também de forma intencional, advinda dos manuais didáticos. Em tais manuais, por sua vez, julgamos bastante enriquecedora a presença desse arcabouço teórico como referência, o que não é o caso da coleção em análise.

Em nosso processo investigativo, ao buscarmos o referencial que subsidia o trabalho com o texto multimodal, em especial para a composição da subseção Leitura da imagem, não localizamos as referências canônicas dos estudos dos multiletramentos e da multimodalidade, mas contribuições de Alberto Manguel. O referido autor é um conhecido romancista argentino que conta com alguns escritos que refletem sobre leitura e escrita, especialmente, leitura e

\section{LINHA D'́GUA}


escrita literárias, mas não a partir de um referencial de base linguística, o que pode ser observado em suas obras, listadas pelas autoras na seção de referências do manual em análise ${ }^{14}$.

Dessa forma, entendemos que esta é a maior das lacunas encontradas em nossa análise: a falta de referencial teórico de cunho linguístico adequado a subsidiar a composição da subseção Leitura da imagem, o que, por conseguinte, incide em: 1. sobrecarregar o professor, que acaba tendo de preencher recorrentes lacunas teóricas a partir de sua própria formação, sem que possa contar com auxílio advindo do manual; 2. levar o professor que tenha menor bagagem relativa aos estudos linguísticos demandados à improvisação de conceitos e a uma porção de achismos de base intuitiva, que tendem a preencher as lacunas deixadas pela falta de conhecimento teórico de forma inapropriada.

Não obstante acreditarmos que a produção de manuais didáticos possa se beneficiar sobremaneira da base teórica trazida neste artigo, não objetivamos apresentar os estudos dos multiletramentos e da multimodalidade como as únicas formas de se explorar o sentido dos textos compostos por múltiplos modos semióticos. A própria Semiótica poderia, certamente, apresentar-se como uma alternativa produtiva às lacunas aqui apresentadas, por exemplo.

Em adição a isso, no escopo do manual de ensino, a orientação ao professor sobre bases teóricas de cunho linguístico relativas à exploração do sentido da imagem tenderia, por sua vez, a influenciar os docentes ao conhecimento e/ou ao aprofundamento em tais estudos, de modo a subsidiar e/ou apontar caminhos para que esse exercício interpretativo do texto multimodal seja realizado com maior embasamento científico.

Nosso intento, em suma, é trazer para a discussão, em sala de aula, uma perspectiva apreciativa, interpretativa e crítica de trabalho com textos compostos por múltiplos modos imagéticos e/ou verbo-visuais que esteja pautada em teorias linguísticas que tanto tem se desenvolvido, especialmente, nas últimas décadas.

\section{Considerações finais}

Ao longo desse texto, trouxemos algumas considerações teóricas, alguns referenciais e categorias de análise relacionados aos multiletramentos, de forma geral, e, de forma mais específica, aos estudos relativos ao letramento crítico, ao letramento visual, à multimodalidade e à Gramática do Design Visual. Procuramos, por meio desse referencial, observar de que modo essas contribuições teóricas materializam-se em uma subseção específica e voltada para análise de textos visuais presente na coleção Português: contexto, interlocução e sentido (ABAURRE; ABAURRE; PONTARA, 2008).

14 MANGUEL, Alberto. Uma história de leitura. São Paulo: Companhia das Letras, 1997.

MANGUEL, Alberto. No bosque do espelho. São Paulo: Companhia das Letras, 2000.

MANGUEL, Alberto. Lendo imagens. São Paulo: Companhia das Letras, 2001.

MANGUEL, Alberto. Os livros e os dias. São Paulo: Companhia das Letras, 2005.

\section{LINHA D'́́GUA}


A partir de nossa investigação, percebemos que as atividades propostas pelas autoras da coleção estabelecem reflexões interessantes e pertinentes acerca da relação entre texto verbal e o texto visual, além de apresentar-se como um trabalho interessante relacionado ao letramento visual dos estudantes. Entretanto, constatamos uma carência sensível de contribuições oriundas dos estudos dos multiletramentos, do letramento crítico, do letramento visual, da multimodalidade e da Gramática do Design Visual. Percebemos, de forma constante, a ausência desses referenciais na motivação do trabalho instituído pelas autoras em relação à leitura de imagens. De fato, nas referências apontadas como base para elaboração do manual de ensino, bem como nas referências apontadas aos professores adotantes como fonte de maiores informações teóricas, não há teóricos da seara dos estudos linguísticos supramencionados.

Soma-se a isso e em função dessa lacuna de conhecimento teórico, a sensação de intuitividade que perpassa as propostas de atividade. Não que tais propostas não façam sentido. Como expusemos na seção de análise, o trabalho proposto pelas autoras tem qualidade inegável, além de uma coerência global bastante pertinente. No entanto, falta-lhe o refinamento teórico na seção em análise em específico, caro ao trabalho com a ciência, independente da área de conhecimento. Essa carência relativa ao referencial acaba por deixar muita coisa a cargo do professor, no sentido de ele precisar fazer as conexões teóricas necessárias, o que não pode ser considerada uma situação adequada.

Em todo caso, a obra cumpre parcialmente seu papel, no sentido de levar o letramento visual de forma intencional e reflexiva à sala de aula, o que não deixa de ser louvável e válido, fazendo-o, ainda, a partir do trabalho pautado na multiplicidade de linguagens (ao valer-se de pinturas e fotografias, por exemplo), e na transculturalidade, pontos centrais à teoria dos multiletramentos.

\section{Referências}

ABAURRE, M. L. M.; ABAURRE, M. B. M.; PONTARA, M. Português: contexto, interlocução e sentido. v.3. Manual do professor. São Paulo: Moderna, 2008.

ALMEIDA, D. B. L. Do texto às imagens: as novas fronteiras do letramento visual. In: PEREIRA, R. C.; ROCA, P. (Orgs.) Linguística Aplicada - um caminho com diferentes acessos. São Paulo: Editora Contexto, 2009, p. 173-202.

BARBOSA, V. F. Multimodalidade e letramento visual: uma proposta de intervenção pedagógica para integrar as habilidades de ler e ver no processo de ensino e aprendizagem de inglês como língua estrangeira. 2017. 414 f. Tese (Doutorado em Linguística Aplicada) Programa de Pós-graduação em Linguística Aplicada, Universidade Estadual do Ceará, Fortaleza, 2017.

BEAUGRANDE, R. New foundations for a science of text and discourse. Freedom of access to knowledge and society through Discourse. Norwood: Ablex, 1997. 
DIONÍSIO, A. P. Gêneros multimodais e multiletramentos. In: KARWOSKI, A. M.; GAYDECZKA, B.; BRITO, K. S. (Orgs.). Gêneros textuais: reflexões e ensino. São Paulo: Parábola Editorial, 2011, p. 137-151.

FRANCO, C. P. Por uma abordagem complexa de leitura. In: TAVARES, K.; BECHER, S.; FRANCO, C. (Orgs.). Ensino de Leitura: fundamentos, práticas e reflexões para professores da era digital. Rio de Janeiro: Faculdade de Letras da UFRJ, 2011. p. 26-48. Ebook. Disponível em: http://www.claudiofranco.com.br/textos/franco_ebook_leitura.pdf Acesso em: 18 nov. 2018.

HALLIDAY, M. A. K. An Introduction to Functional Grammar. $1^{\text {a }}$ ed. Londres: Arnold, 1985.

HALLIDAY, M. A. K; MATTHIESSEN, C. M. I. M. An Introduction to Functional Grammar. $4^{\mathrm{a}}$ ed. Londres: Routledge, 2014.

HANKS, W. F. O que é contexto? In: BENTES, A.C.; REZENDE, R.C.; MACHADO, M.A.R. (Orgs.). Língua como prática social: das relações entre língua, cultura e sociedade a partir de Bourdieu e Bakhtin. São Paulo: Cortez, 2008. p. 169-203.

JANKS, H. The importance of critical literacy. English teaching: Practice and Critique, v. 11, n. 1. p. 150-163, mai. 2012.

KRESS, G.; VAN LEEUWEN, T. Reading images: the grammar of visual design. London, New York: Routledge, 1996.

NEW LONDON GROUP. A pedagogy of multiliteracies: designing social futures. Harvard Educational Review, v. 66, n. 1, p. 60-93, Spring 1996. Disponível em http://newarcproject.pbworks.com/f/Pedagogy\%2Bof\%2BMultiliteracies_New\%2BLondon\% 2BGroup.pdf. Acesso em: 20 nov. 2018.

ROJO, R. Gêneros discursivos do círculo de Bakhtin e os multiletramentos. In: ROJO, R. (Org.) Escol@Conectada - os multiletramentos e as TICs. São Paulo: Parábola, 2013.

STOKES, S. Visual literacy in teaching and learning: a literature perspective. Electronic journal for the integration of technology in education, v.1, n.1, p. 10-19, 2002.

STREET, Brian. Letramentos sociais: abordagens críticas do letramento no desenvolvimento, na etnografia e na educação. Tradução Marcos Bagno. 1ª . ed. São Paulo: Parábola Editorial, 2014.

VAN LEEUWEN, T. Multimodality. In: SIMPSON, J. (Ed.) The Routledge handbook of applied linguistics. London/New York: Routledge, 2011, p. 668-682.

Recebido: 22/08/2020.

Aprovado: 13/02/2021. 